\title{
Pengendalian Banjir dengan Konsep Model Desa Spons Berbasis Ecodrains (studi kasus: DAS Kamoning Kabupaten Sampang, Madura)
}

\author{
Control of Flood with the Concept of Ecodrains-Based Sponge Village Mode \\ (Sampang Regency study, Madura)
}

\author{
Zaiful Muqaddas $^{1}$, Zaenal Kusuma ${ }^{2}$, Runi Asmaranto ${ }^{3}$, Bagyo Yanuwiadi ${ }^{4}$ \\ ${ }^{1}$ Program Doktor Ilmu Lingkungan, Pascasarjana, Universitas Brawijaya, Malang 65145, Indonesia \\ ${ }^{2}$ Jurusan Ilmu Tanah Fakultas Pertanian, Universitas Brawijaya,65145, Malang, Indonesia \\ ${ }^{3}$ Jurusan Teknik Pengairan Fakultas Teknik, Universitas Brawijaya,65145, Malang, Indonesia \\ ${ }^{4}$ Jurusan Biologi Fakultas MIPA, Universitas Brawijaya,65145, Malang, Indonesia
}

\section{Article info:}

Kata kunci:

Banjir, reduksi, pola ruang, desa spons

Keywords:

Floods, reduction, spatial pattern, sponge village

Article history:

Received: 30-10-2020

Accepted: 27-05-2021

${ }^{*}$ Koresponden email: zaifulmuqaddas8@gmail.com

\begin{abstract}
Abstrak
DAS Kamoning sering mengalami banjir yang terjadi hampir tiap tahun, permasalahan ini karena tata guna lahan DAS didominasi oleh area tegalan seluas 55,48\% yang menjadi area limpasan, jika ditambahi dengan luas permukiman $15,59 \%$ yang belum dibangun sistem ecodrains, maka luas area limpasan air hujan yg menjadi penyebab banjir menjadi $71 \%$ dari luas DAS. Kondisi ini semakin tidak proporsinal ketika jenis tanah di DAS Kamoning $72 \%$ juga didominasi tanah kategori D (laju infiltrasi sangat lambat). Melalui model desa spons berbasis ecodrains dilakukan perubahan pola ruang desa yang secara otomatis merubah pola ruang di DAS. Dengan pengaturan $40 \%$ luas vegetasi di setiap desa dengan mngurangi area tegalan, penambahan sumur resapan disetiap rumah/bangunan beratap dan pembangunan sumur injeksi di lahan pertanian tiap 0,16 ha. Hasil analisanya dibuktikan debit limpasan banjir dapat direduksi hingga 78,14\% dan berada dibawah kapasitas Sungai Kota Sampang.
\end{abstract}

\begin{abstract}
The Kamoning watershed often experiences flooding that occurs almost every year, this problem is because the land use of the watershed is dominated by a dry area of $55.48 \%$ which becomes a runoff area, if added with residential area of $15,59 \%$ which has not yet been built an ecodrains system the area of rainwater runoff which causes flooding tobe $71 \%$ of the watershed area. This condition is increasingly disproportionate when the soil type in the Kamoning watershed is $72 \%$ dominated by category D soil (infiltration rate is very slow). Throught the ecodrains -based sponge village model, changes to village spatial pattern are carried out Which automatically changes the spatial pattern in the the watershed. By Controlling $40 \%$ of the vegetation area in each village by reducing the moor area, adding infiltration wells in each roofed building and constructing injection wells on agricultural land every 0,16 ha. The result of the analysis prove runoff can be reduced by $78,14 \%$ and is below the capacity of the Sampang City River. .
\end{abstract}

Kutipan: Muqaddas, Z., Kusuma, Z., Asmaranto, R.,Yanuwiadi, B., Pengendalian Banjir dengan Konsep Model Desa Spons Berbasis Ecodrains, Jurnal Teknik Pengairan. https://doi.org/10.21776/ub.pengairan.2021.012.01.04 


\section{Pendahuluan}

DAS Kali Kamoning Kabupaten Sampang memilki luas 35,421.15 Ha, berbentuk seperti kipas dan bertipe radial. Tipe radial menurut Sosrodarsono dan Takeda (2003) anak-anak sungainya mengkonsentrasi kesuatu titik secara radial dan akan mempunyai banjir besar didekat titik pertemuan anak-anak sungai. Kecamatan Sampang seringkali terjadi banjir besar karena lokasi dihilir DAS dan menjadi pertemuan anak-anak sungai Kamoning. Hasil pencatatan dengan angka curah hujan rata-rata di DAS Kamoning antara 40-50 mm saja akan menyebabkan banjir di Kota Sampang. Kondisi tata guna lahan (land use) DAS Kamoning juga tidak proporsinal karena didominasi oleh lahan tegalan yang menjadi area limpasan seluas $55.48 \%$, lahan pertanian $18.97 \%$ dan lahan permukiman $15.59 \%$ sementara lahan vegetasi sebagai area resapannya sangat minim hanya $9.97 \%$ dari Luas DAS. Dengan kondisi land use tersebut diatas akan menibulkan limpasan permukaan yang dapat berpotensi menjadi banjir hal ini sesuai dengan yang disampaikan Bisri (2009) "Jika prosentase tutupan lahan oleh tanaman yang menyerap air sangat rendah atau tutupan lahan dengan bahan kedab air lebih luas dibandingkan tutupan lahan yang dapat menyerap atau tembus air kedalam tanah akan menimbulkan limpasan besar atau genangan tinggi.

Berbagai kegiatan pengendalian banjir yang dilakukan pemerintah Kabupaten Sampang, termasuk Pemerintah provinsi Jawa timur dan Pemerintah Pusat dalam mengatasi banjir namun sifatnya hanya mengurangi dan belum dapat menyelesaikan banjir secara total dan beberapa kegiatan besar seperti rencana pembuatan bendungan dan floodway (sodetan) tidak dapat dilaksanakan karena terkendala dengan pembebasan tanah dan hanya menjadi program perencanaan dan studi jangka menengah yang tidak dapat terealisasi dengan baik. Permasalahan banjir disampang juga karena jenis tanah di DAS kamoning di dominasi Jenis tanah dengan kategori sangat lambat dalam menyerap air hujan. Kondisi tanah DAS kamoning terutama di daerah hulu, termasuk dalam kategori lajuninfiltrasi lambat (Agustini, 2016).

Menurut triwidyanto (2014) terjadinya banjir dikabupaten Sampang disebabkan karena factor penggunaan lahan dengan bobot 0.363 kemudian curah hujan 0.264 sistem lahan 0.236 kemiringan lereng 0.096 dari hasil perhitungan rata-rata spasial analiss composite mapping. Informasi yang beredar dimasyarakat bahwa banjir dikota sampang dikarenakan juga pengaruh pasang surut air laut juga tidak semuanya benar karena hasil penelitian dari Anis (2016) menyebutkan bahwa "Pengaruh back water (pasang air laut) dimuara sungai kamoning pada jarak hilir ke hulu $537 \mathrm{~m}$ muka air sungai hanya bertambah $0.6 \mathrm{~m}$, sementara jika jaraknya menjadi 655 meter (hilir ke hulu) muka air laut turun menjadi $0.25 \mathrm{~m}$ ".

Dengan melihat gambaran diatas penelitian ini bertujuan untuk mengatasi masalah banjir yang terjadi di Kota Sampang, identifikasi proporsi tataguna lahan yang baik untuk model desa resapan agar limpasan yang terjadi tidak melebihi kapasitas sungai. Sebagaimana disampaikan oleh bhakti (2008) "Untuk mereduksi jumlah aliran permukaan salah satunya dengan sistem Penataan ruang kawasan yang dilakukan dengan menerapkan Perbandingan yang proporsional antara daerah terbangun dan Daerah Resapan, maka debit limpasan yang timbul dalam suatu kawasan dapat dikendalikan".

\section{Bahan dan Metode}

\subsection{Data atau bahan}

Data yang dibutuhkan dalam penelitian ini yakni, peta DAS kamoning dan data tata guna lahan disetiap desa atau perdesa yang didapat dari Pemerintahan Desa, dari Kecamatan atau dari Badan Pusat Statistic (BPS), data tata guna lahan teresebut difikuskan pada 4 data penggunaan lahan dominan di desa yakni data luasan sawah pertanian, luas lahan tegalan, luas lahan permukiman dan luas lahan vegetasi atau hutan yang selanjutnya masing-masing luasan lahan dikelompokkan persubdas. Jumlah desa dalam kawasan DAS Kamoning teridentifikasi sebanyak 51 Desa 6 kelurahan sebagaimana peta DAS kamoning yang dikelompokkan perwilayah kecamatan (Gambar 1), walaupun tidak semua desa dalam wilayah kecamatan masuk dalam kawasan DAS Kamoning. Pada Gambar 1 dapat dilihat Peta data desa yang masuk wilayah DAS Kamoning. 


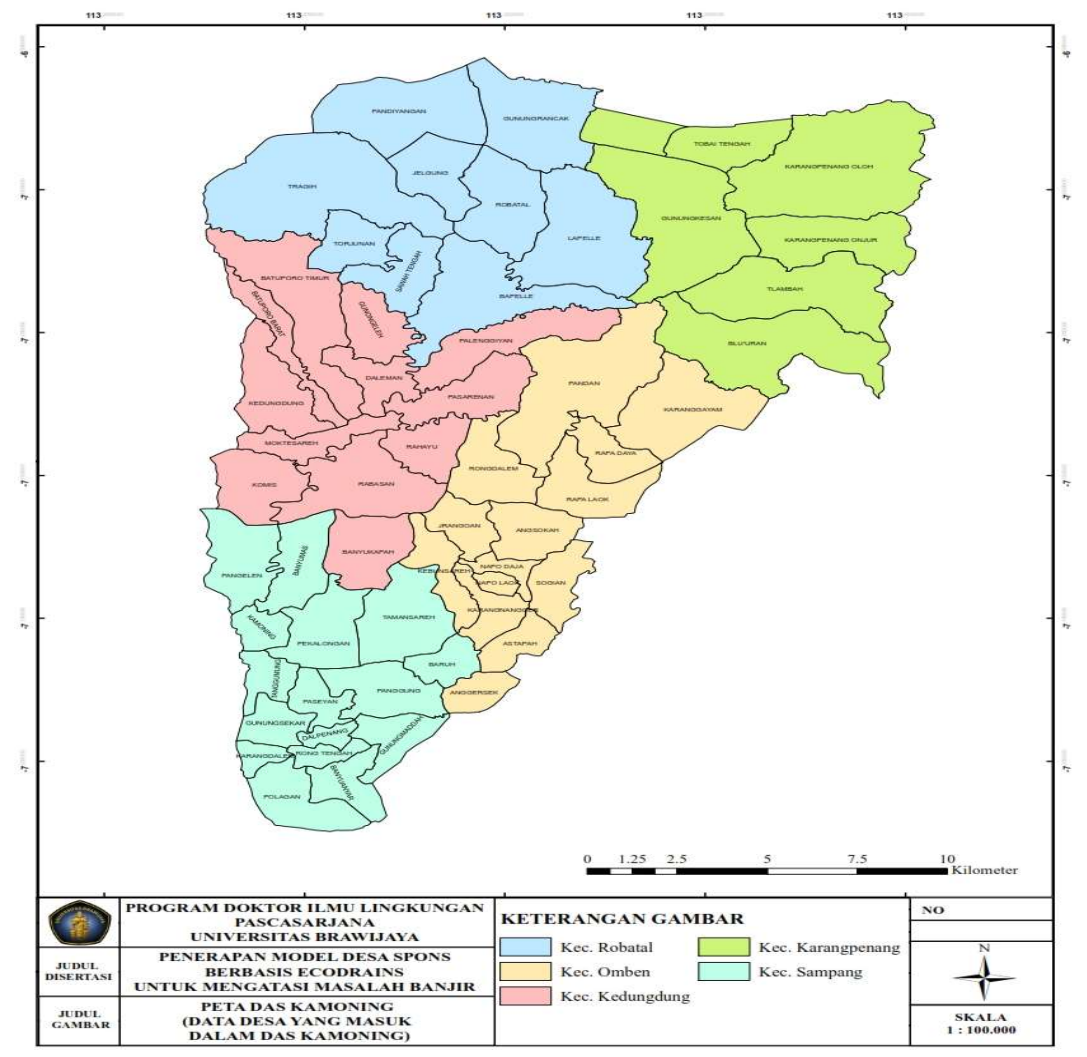

Gambar 1. Peta desa yang masuk dalam kawasan DAS Kamoning

Data selanjutnya adalah data sebaran jenis tanah secara hidrologi melalui peta sebaran tanah yang nantinya diklasifikasikan secara kelompok hidrologi menurut klasifikasi USDA yakni penggolongan tanah dalam 4 (empat) kelas antara lain kelas A, B , C atau D. Asdak (2002:84), menjelaskan bahwa berdasar sifat aliran laju infiltrasinya tanah dikelompokkan menjadi 4 kelas hidrologi diataranya kelompok kelas A adalah tanah dengan tipe laju infiltrasi cepat, kelompok B laju infiltasi sedang, kelompok $\mathrm{C}$ adalah laju infiltrasi lambat sedang kelompok kelas D adalah tanah laju infiltrasi sangat lambat dalam meloloskan atau menyerap air hujan. Karena terdapat 51 Desa, 6 kelurahan dalam DAS Kamoning maka penentuan nilai Curve Number $(\mathrm{CN})$ komposit berdasar kelompok jenis tanah dan tata guna lahan di tiap desa dalam kelompok SubDAS. Data lainnya yang dibutuhkan dalam penelitian ini adalah data curah hujan yang diambil pada pencatatan selama 20 tahun di DAS Kamoning yang meliputi 5 area kecamatan, yakni stasiun penakar hujan Karang penang, Stasiun Robatal, Stasiun kedungdung, Stasiun Omben dan Stasiun Penakar hujan Sampang

\subsection{Metode}

Metode penelitian ini dimulai dengan identifikasi karakteristik dan laju infiltrasi tanah untuk mengetahui Jenis tanah secara hidrologi di DAS Kamoning, mengelompokkan penggunaan lahan (Land use) ditiap desa, dengan membagi penggunaan lahan di desa menjadi 4 lahan dominan, yakni lahan tegalan, lahan vegetasi (hutan), lahan pertanian dan lahan permukiman. Untuk penggunaan lahan lainnya rata-rata luasannya dibawah $1 \%$ sehingga dalam penelitian ini subtitusikan (dimasukkan) kedalam 4 penggunaan lahan dominan tersebut dengan melihat kemiripan fungsi penggunaan lahannya sehingga luas 1 desa $(\mathrm{y})$ sama dengan luas permukiman $\left(\mathrm{x}_{1}\right)$ ditambah luas Pertanian $\left(\mathrm{x}_{2}\right)$ ditambah luas hutan $\left(\mathrm{x}_{3}\right)$ dan ditambah luas tegalan $\left(\mathrm{x}_{4}\right)$ atau $\mathrm{y}=\mathrm{x}_{1}+\mathrm{x}_{2}+\mathrm{x}_{3}+\mathrm{x}_{4}$. Dengan mengetahui komposisi luasan penggunaan lahan tiap desa maka dapat merubah pola ruang atau tata guna lahan didesa tersebut dan secara otomatis pula akan merubah tata guna lahan dalam tiap subdas dan merubah tata guna lahan dalam satu kawasan DAS. Komposisi tata guna lahan eksisting dalam 
tiap desa, diketahui luas tegalan mendominasi luas penggunaan lahan melebihi $50 \%$ dari luas desa (Gambar 2).

\section{Komposisi Tata Guna lahan Tiap Desa (Pola Ruang Desa ) di DAS Kamoning}

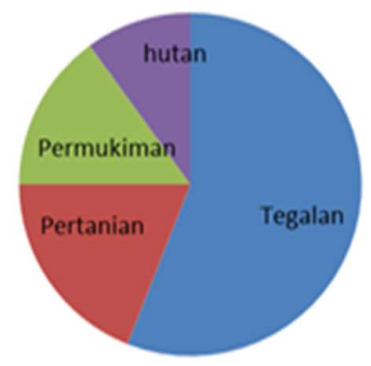

Gambar 2. Komposisi tata guna lahan eksisting Desa di DAS Kamoning

Langkah selanjutnya menentukan jumlah subdas berdasar aliran sungai utama, kemudian tiap desa dikelompokkan berdasarkan kelompok subdas lalu menentukan luasan tata guna lahan didesa dalam kelompok subdas, demikian pula kelompok jenis tanah yang digolongkan berdasarkan kelas hidrologi A, B, C atau D yang telah dipetakan tiap desa dan dikelompokkan berdasar kelompok subdas. Melalui skenario Rencana Pola Ruang Desa (RPRD) akan merubah tata guna lahan di setiap desa, yang secara otomatis akan merubah tata guna lahan di tiap subdas dan seluruh kawasan DAS (Gambar 3).

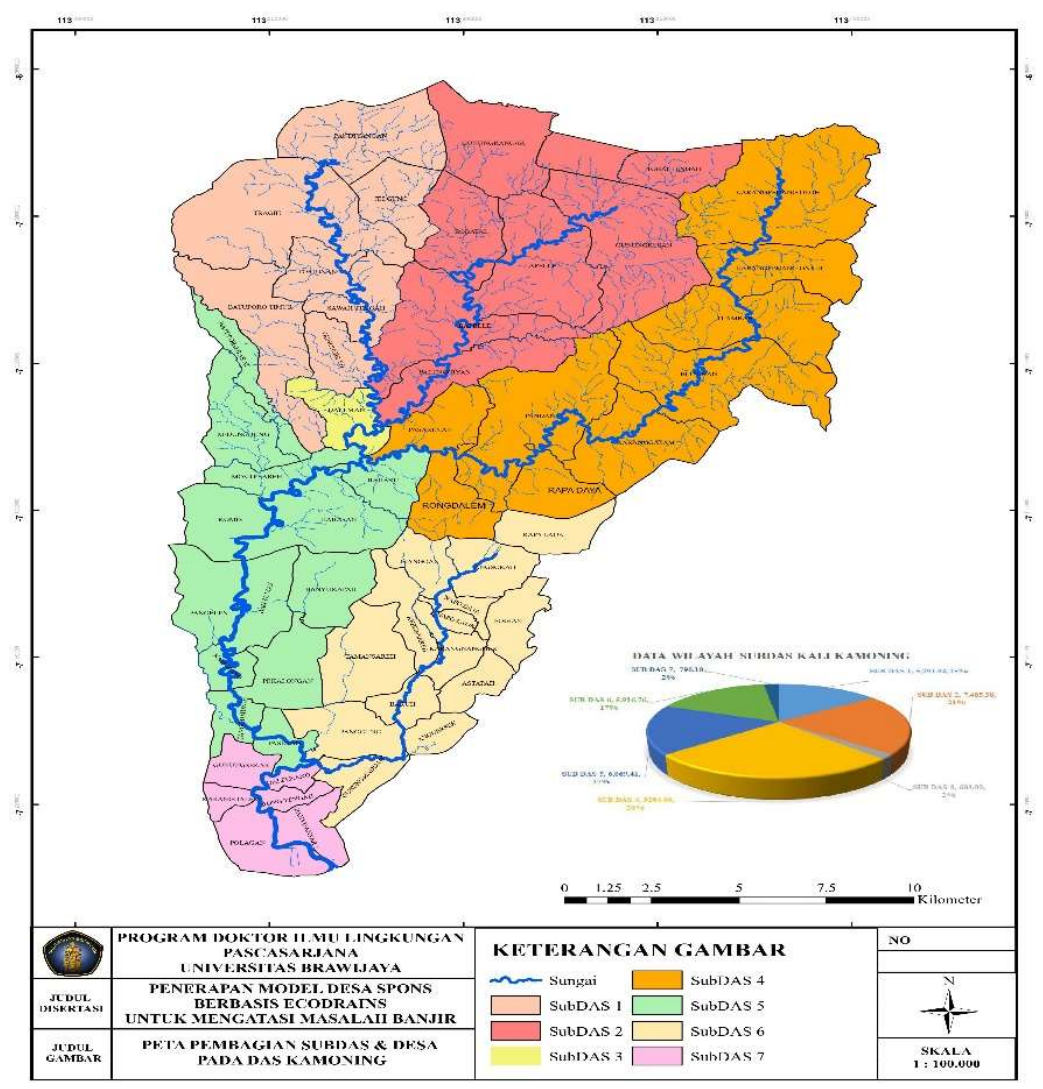

Gambar 3 Peta Pembagian SubDAS kali Kamoning Kab.Sampang 
Perubahan pola ruang desa ini yakni dengan meningkatkan proporsi jumlah vegetasi ditiap desa dengan menggunakan 4 skenario perubahan, sekenario I penambahan vegetasi hingga $20 \%$ dari luas Desa, skenario 2 menambah vegetasi hingga 30\% dari luas Desa, skenario 3 menambah luasan vegetasi hingga $40 \%$ dari luas desa, kemudian skenario 4 yakni vegetasi dibuat luasan $50 \%$. Perubahan penambahan vegetasi dilakukan dengan mengurangi luas lahan tegalan ditiap desa sehingga menambah luasan vegetasi baik berupa hutan atau kebun disetiap desa dalam kelompok subdas sehingga semua kawasan DAS juga terjadi perubahan. Dari klasifikasi jenis tanah dan perubahan pola ruang (tata guna lahan) desa akan didapatkan perubahan nilai Curve Number (CN). Nilai CN ini yang menjadi indeks debit limpasan aliran permukaan dari parameter tata guna lahan dan jenis tanah dan menjadi input dalam analisa dengan software HEC-HMS 3.5. Berikut contoh penentuan nilai $\mathrm{CN}$ pada Tabel 1 analisa perhitungan Curve Number (CN) komposit pada subdas 1 Kali Kamoning.

Tabel 1. Analisa perhitungan Curve Number (CN) Komposit Subdas 1 Kali kamoning

\begin{tabular}{|c|c|c|c|c|c|c|}
\hline No & $\begin{array}{l}\text { Jenis Penggunaan } \\
\text { Lahan Sub DAS } 1\end{array}$ & Jenis Tanah & $\begin{array}{l}\text { Luas lahan } \\
\text { (ha) }\end{array}$ & $\begin{array}{c}\text { Kelompok } \\
\text { Tanah }\end{array}$ & $\begin{array}{c}\text { Nilai } \\
\text { Curve } \\
\text { Number }\end{array}$ & Lahan $x$ CN \\
\hline & 1 & 2 & 3 & 4 & 5 & $(3 \times 5)$ \\
\hline 1 & Sawah /Pertanian & $\begin{array}{l}\text { Kompleks Mediteran, } \\
\text { Grumusol, Regosol } \\
\text { dan Litosol }\end{array}$ & 568.81 & $\mathrm{D}$ & 81 & $46,073.81$ \\
\hline 2 & Permukiman & $\begin{array}{l}\text { Kompleks Mediteran, } \\
\text { Grumusol, Regosol } \\
\text { dan Litosol }\end{array}$ & 518.12 & $\mathrm{D}$ & 85 & $44,040.21$ \\
\hline 3 & $\begin{array}{l}\text { Tanah Ladang } \\
\text { (tegalan) }\end{array}$ & $\begin{array}{l}\text { Kompleks Mediteran, } \\
\text { Grumusol, Regosol } \\
\text { dan Litosol }\end{array}$ & $3,012.93$ & $\mathrm{D}$ & 89 & $268,151.05$ \\
\hline 4 & $\begin{array}{l}\text { Hutan/vegetasi } \\
\text { tanaman jarang }\end{array}$ & $\begin{array}{l}\text { Kompleks Mediteran, } \\
\text { Grumusol, Regosol } \\
\text { dan Litosol }\end{array}$ & $1,192.18$ & $\mathrm{D}$ & 77 & $91,797.61$ \\
\hline & & & $5,292.04$ & & & $450,062.69$ \\
\hline & \multicolumn{5}{|c|}{ Nilai $\mathrm{CN}$ subDAS 1} & $85,045.00$ \\
\hline
\end{tabular}

Langkah selanjutnya yakni curah hujan harian maksimum dari data pencatatan 20 tahun dikonversikan menjadi hujan rancangan (periode ulang) yang menjadi input data dalam analisa perhitungan debit puncak limpasan melalui software Hydrologic Enggineering Center-Hydrologic Modelling System (HEC-HMS). HEC-HMS dapat mentranformasi hujan menjadi limpasan dengan mengakomodir karakteristik DAS seperti tata guna lahan, jenis tanah dan tanaman penutup hingga didapatkan debit puncak limpasan (Qth) dengan periode ulang $\mathrm{Q}_{2,5 \text { th }}, \mathrm{Q}_{5 \text { th }}, \mathrm{Q}_{10 \text { th }}, \mathrm{Q}_{25 \text { th }}, \mathrm{Q}_{50 \text { th }}$ dan $\mathrm{Q}_{100 \text { th }}$. Dari running HEC-HMS juga didapatkan debit reduksi limpasan dari skenario perubahan pola ruang desa melalui penambahan vegetasi $\left(\mathrm{Q}_{\mathrm{rv}}\right)$. Kombinasi reduksi dari kontruksi ecodrainase ditambahkah ketika reduksi dengan vegetasi $\left(\mathrm{Q}_{\mathrm{rv}}\right)$ belum maksimal dalam mereduksi debit puncak periode ulang sehingga diperlukan kontruksi ecodrainase. Dalam penelitian ini dipilih sumur resapan (Qsr) dan sumur injeksi (Qsi) karena kedua ecodrainse tersebut tidak memerlukan pembebasan tanah serta efektif dalam menyimpan dan meresapkan air hujan. Dengan pengaturan tata ruang desa maka model spons (Qms) bekerja dengan meresapkan air hujan disetiap penggunaan lahan di desa agar limpasan terjadi tidak melampaui kapasitas sungai $(\mathrm{Qks})$ Sehingga $\mathrm{Qms}=\mathrm{Qrv}+\mathrm{Qsr}+\mathrm{Qsi}$ dimana $\mathrm{Qth}-\mathrm{Qms}<$ Qks. 


\section{Hasil dan Pembahasan}

Dari hasil analisa penentuan kelompok tanah didapatkan bahwa 10\% tanah di DAS Kamoning tergolong kelompok B (kelompok sedang), $18 \%$ diantaranya tergolong kelompok C yakni kelompok tanah lambat dalam laju infiltrasinya dan $72 \%$ jenis tanah di DAS Kamoning tergolong dalam Kelas Hidrologi D, yakni tanah yang tergolong memilki karakter laju Infiltrasi sangat lambat, banyak kandungan tanah liat, potensi air limpasan tinggi. Kelompok Jenis tanah D inilah yang berpotensi menyebabkan banjir dikota Sampang. Hal tersebut dibuktikan Dari hasil running HEC-HMS terhadap kondisi eksisting DAS Kamoning yang terdiri atas 72\% jenis tanah kategori D ditambah penggunaan lahan tegalan yang mendominasi hingga 55.48\% dari luas DAS didapatkan debit puncak pada kondisi eksisting untuk periode ulang $Q_{2 t h}=161 \mathrm{~m}^{3} / \mathrm{dtk}, \mathrm{Q}_{5 \mathrm{th}}=240.6 \mathrm{~m}^{3} / \mathrm{dtk}, \mathrm{Q}_{10 \mathrm{th}}=317 \mathrm{~m}^{3} / \mathrm{dtk}$, $\mathrm{Q}_{25 \mathrm{th}}=446.1 \mathrm{~m}^{3} / \mathrm{dtk}$ dan $\mathrm{Q}_{50 \mathrm{th}}=569.2 \mathrm{~m}^{3} / \mathrm{dtk}$, yang mana semua debit puncak limpasan berada diatas nilai debit kapasitas sungai (garis datar) yang nilainya $Q_{\mathrm{KS}}=136.5 \mathrm{~m}^{3} / \mathrm{dtk}$ sebagaimana dapat diperhatikan pada gambar 4 Hidrograp hubungan debit puncak banjir dan debit kapasitas sungai berikut ini.

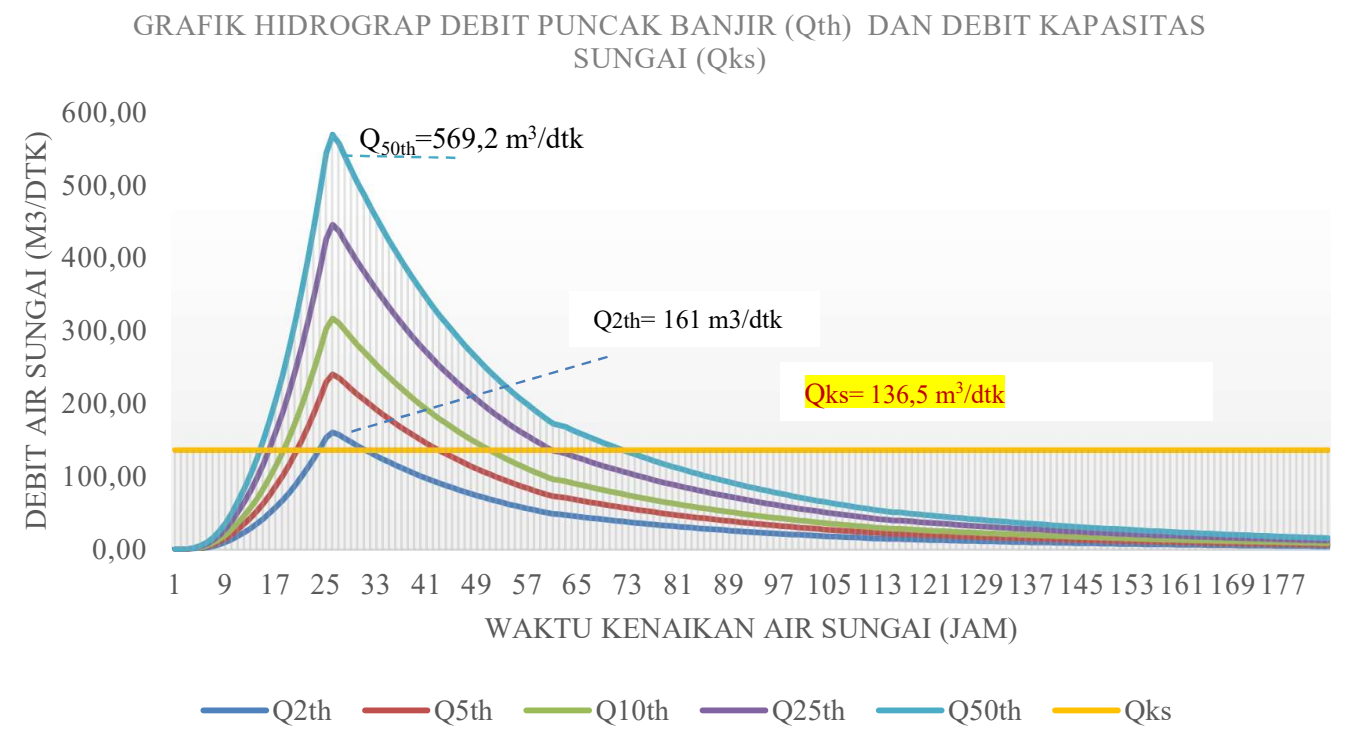

Gambar 4. Hidrograp hubungan debit puncak banjir dan kapasitas sungai

Dengan melihat gambar 4 diatas dapat diketahui bahwa apabila terjadi curah hujan dengan periode ulang terkecil saja $R_{2}$ tahunan yang menghasilkan debit sungai $Q_{2 t h}=161 \mathrm{~m}^{3} / \mathrm{dtk}$. Sungai Kota Sampang akan terjadi banjir karena debit alirannya sudah melampaui debit kapasitas sungai $\mathrm{Q}_{2 \mathrm{th}}>\mathrm{Q}_{\mathrm{KS}}=136.5 \mathrm{~m}^{3} / \mathrm{dtk}$.

Dengan kondisi tersebut diatas maka sebagaimana disampaikan dalam pasal 38 Peraturan Pemerintah no. 38 tahun 2011 tentang sungai untuk mencegah banjir dilakukan dengan peningkatan kapasitas sungai dihilir dan atau dibuat sistem resapan diarea hulu DAS area tangkapan hujan. Peningkatan kapasitas sungai dihilir saat ini tidak memungkinkan karena aliran sungai berada diarea Kota Sampang sehingga terkendala dengan pembebasan tanah. metode terbaik yakni dengan reduksi (pengurangan) banjir diarea hulu dan tengah DAS. Reduksi diarea hulu yakni dilakukan dengan skenario penambahan vegetasi. Adanya vegetasi mempengaruhi terhadap limpasan permukaan yakni dapat menghalangi jalannya air larian dan memperbesar jumlah air yang tertahan diatas permukaan tanah (surface detention), sehingga dapat menurunkan laju limpasan permukaan (Harisuseno, 2014).

Dengan 4 Skenario modelling menggunakan software HEC-HMS maka tata guna lahan di setiap desa dirubah dalam empat model skenario perubahan tata guna lahan, perubahan tata guna lahan di setiap desa secara otomatis merubah tata guna lahan diseluruh kawasan DAS kamoning. Adapun skenario penambahan vegetasi dan hasil reduksi dari penambahan vegetasi untuk $\mathrm{Q}_{2 \text { th }}$ adalah sebagai berikut: Skenario 1 luas vegetasi dibuat 20\% dari luas DAS dihasilkan debit tereduksi $\mathrm{Q}_{\mathrm{rv}}=147.8$ 
$\mathrm{m}^{3} / \mathrm{dtk}$, skenario 2 luas vegetasi $30 \%$ didapatkan debit puncak yang tereduksi menjadi $\mathrm{Q}_{\mathrm{r} 22}=140.6$ $\mathrm{m}^{3} / \mathrm{dtk}$, Skenario 3 luas vegetasi $40 \%$ didapatkan debit tereduksi vegetasi $\mathrm{Q}_{\mathrm{r} v 3}=134.4 \mathrm{~m}^{3} / \mathrm{dtk}$ dan skenario 4 luas vegetasi $50 \%$ didapatkan Qrv4=128.6 $\mathrm{m}^{3} / \mathrm{dtk}$. Dengan bertambahnya luas hutan (vegetasi), maka debit puncak banjir juga mengalami penurunan, pada skenario 3 (luas hutan $40 \%$ ) didapatkan kondisi ideal dimana terjadi pertemuan grafik penambahan luas hutan dengan penurunan debit puncak (Gambar 5).

\section{Debit Puncak Q2th dan Penambahan Luas Hutan}

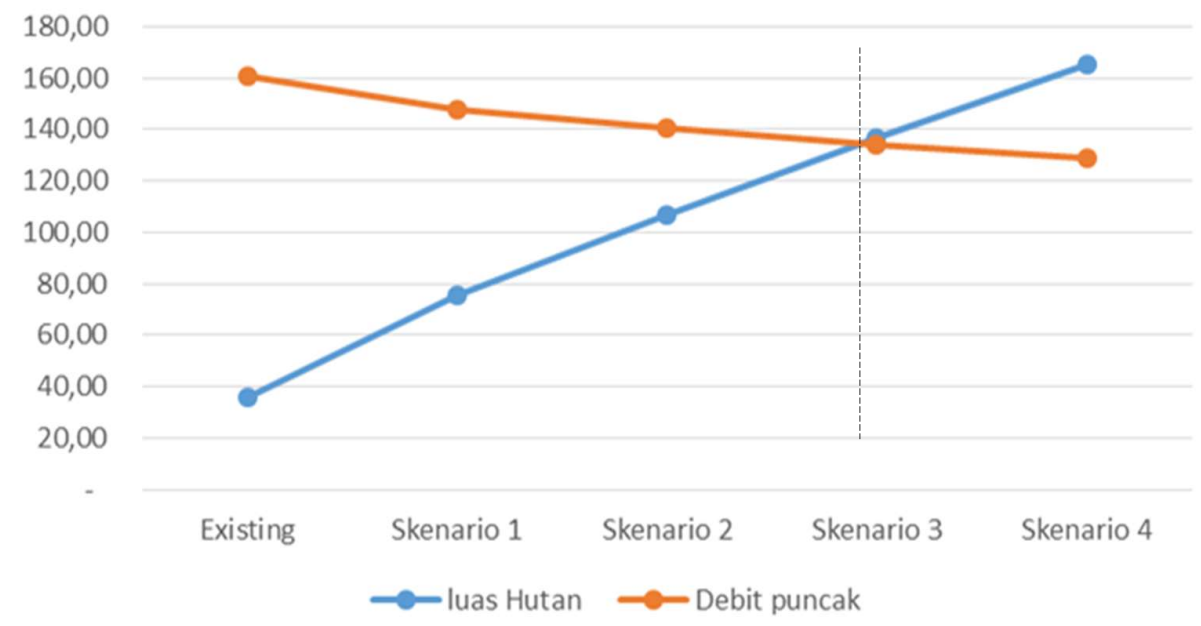

Gambar 5. Grafik debit puncak banjir dengan Penambahan Luas hutan

Dari Gambar 5 dapat diketahui bahwa semakin luas penambahan vegetasi (hutan) pada suatu DAS maka nilai debit reduksi banjirnya semakin besar sehingga debit limpasan (runoff) yang terjadi makin turun atau berkurang (mengecil). Dari Gambar 5 juga dapat disimpulkan bahwa luas lahan vegetasi yang baik untuk hutan atau kebun atau gabungan keduanya dalam rangka mengurangi limpasan hujan di tiap desa atau seluruh kawasan DAS yakni seluas $40 \%$ dari luas totalnya, skenario 3 dengan luas vegetasi hutan hingga $40 \%$ adalah kondisi prosentase luasan terbaik untuk kawasan DAS. Dengan hal tersebut pada model kombinasi desa spons ini luas penambahan vegetasi $40 \%$ ditetapkan sebagai kombinasi luasan yang layak dan optimum dalam mereduksi banjir untuk tata guna lahan pada penggunaan tanaman.

Namun dari hasil running HEC-HMS sistem reduksi banjir hanya dengan perluasan vegetasi (hutan) saja memiliki kemampuan terbatas dalam mengurangi limpasan air banjir ini karena jenis tanah di DAS Kamoning 72\% nya tergolong kelompok hidrologi D (laju infiltrasi sangat lambat). Skenario 3 penambahan vegetasi hingga 40\% dari luas desa/DAS tersebut hanya dapat mereduksi $\mathrm{Q}_{2 \text { th }}$ hingga aman dibawah kapasitas Sungai atau dengan kata lain dapat mencegah jenis banjir sekala kecil (gambar 6). Sementara untuk debit puncak $\mathrm{Q}_{5 \text { th, }} \mathrm{Q}_{10 \text { th }}, \mathrm{Q}_{25 \text { th }}$, dan $\mathrm{Q}_{50 \text { th }}$ dengan penambahan vegetasi sampai $50 \%$ dari luas DAS tetap saja tidak dapat mengatasi banjir dan hanya mereduksi banjir hingga $11.8 \%$ saja. Oleh karenanya diperlukan metode ecodrainase lain untuk menambah jumlah reduksi banjir agar semua limpasan yang terjadi di DAS dapat lebih maksimal dalam mengurangi dan mencegah terjadinya banjir. Hasil reduksi puncak banjir dengan hanya penambahan vegetasi dapat dilihat pada Gambar 6 grafik hidograf debit puncak setelah penambahan vegetasi $40 \%$ berikut ini. 


\section{HIDROGRAF DEBIT PUNCAK SETELAH PENAMBAHAN VEGETASI $40 \%$ (DEBIT BANJIR TEREDUKSI DENGAN SKENARIO 3)}

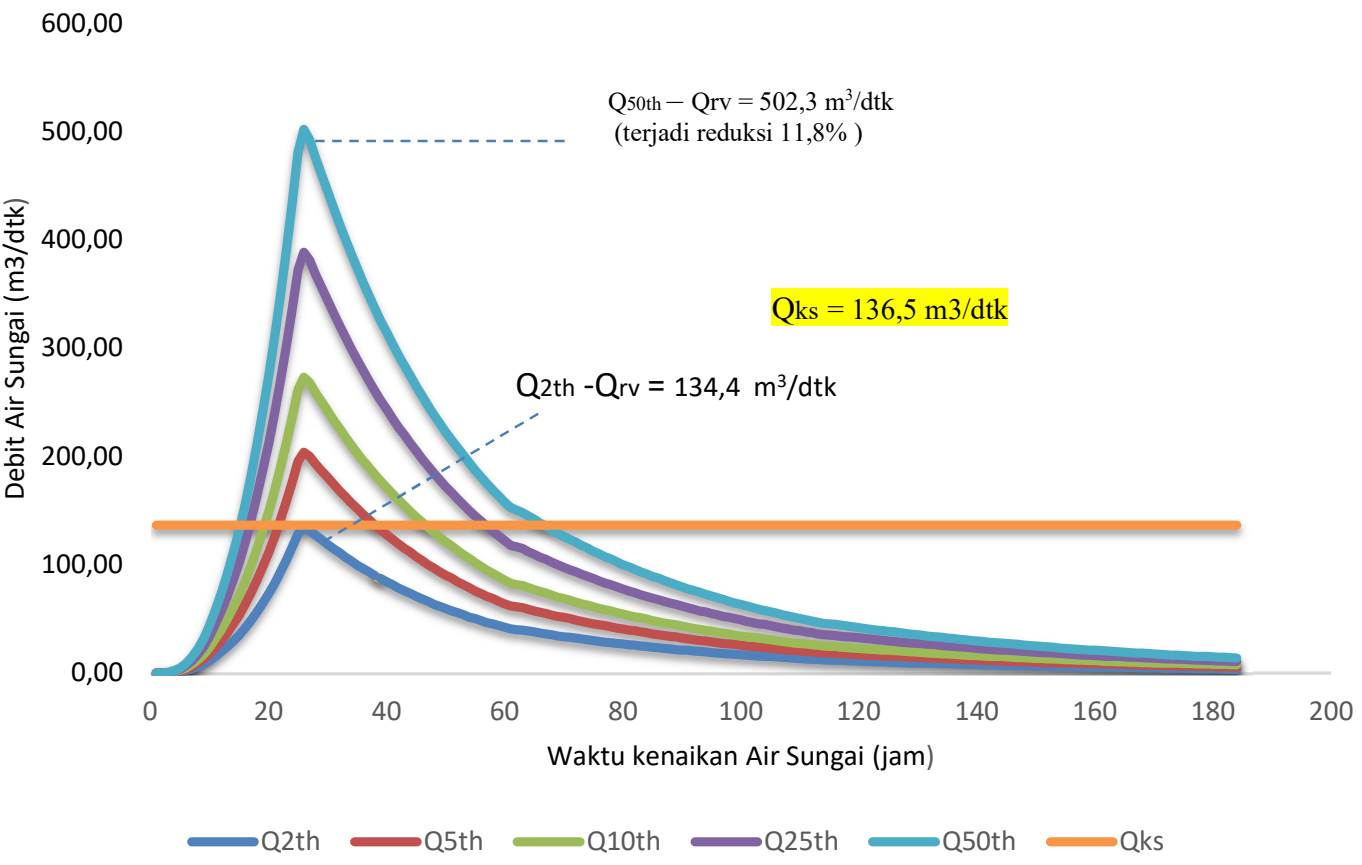

Gambar 6. Hidograf debit puncak setelah penambahan vegetasi $40 \%$ skenario 3

Dengan memperhatikan Gambar 6 grafik hidrograf diatas dapat diketahui bahwa Kota Sampang tetap tidak aman jika terjadi banjir setara Q5th keatas. Apabila dilakukan penambahan vegetasi hingga $100 \%$ juga tidak mungkin karena didesa dibutuhkan adanya penggunaan lahan lainya seperti area sawah pertanian, permukiman termasuk lahan tegalan juga tetap dibutuhkan karena menjadi wilayah peternakan atau pengembalaan hewan ternak atau area rumput meskipun perlu dibatasi luasannya. Oleh karenanya atas ketebatasan kemampuan reduksi oleh tanaman/vegetasi karena jenis tanah di DAS Kamoning didominasi kelompok tanah Kelas D, diperlukan kombinasi resapan lain untuk mereduksi limpasan banjir agar debit aliran yang ada dapat direduksi hingga berada dibawah kapasitas sungai.

Konsep Model Desa Spons dalam penelitian ini menjadi alternatif solusi yang baik dalam mengatasi masalah banjir karena mengadobsi 5 pilar pengelolaan SDA sebagaimana diatur dalam UU No.7 tahun 2004 yakni sistem konservasi lahan yang baik, pendayagunaan SDA, pengendalian daya rusak air, sistem informasi berjenjang dan Pemberdayaan masyarakat di desa. desa spons adalah ruang wilayah yang memperbanyak resapan air hujan dengan cara mengurangi wilayah (lahan) yang berpotensi menjadi penyebab banjir dengan menambah sistem ecodrainase di setiap penggunaan lahan tersebut. Prinsip kerjanya yakni melakukan perubahan tata ruang desa dengan cara setiap penggunaan lahan di desa harus berfungsi seperti spons yakni memiliki kemampuan dalam menyerap dan menyimpan limpasan air hujan dengan membatasi penggunaan lahan tegalan optimalisasi penggunaan hutan (vegetasi) hingga 40\% dari luas Desa sebagai area resapan dan menambah struktur peresap laiinya dipenggunaan lahan pada permukiman dan sawah. Sebagaimana disampaikan oleh Sugandi (2007)," Untuk mengatasi terjadinya banjir dengan mengurangi limpasan permukaan, dengan cara setiap unit penggunaan lahan harus meresapkan curah hujan".

Model Desa Spons (Qms) dalam penelitian ini membagi pola ruang desa kedalam 4 lahan dominan dan setiap penggunaan lahannya dibangun sistem resapan dengan pola kombinasi sebagai berikut lahan tegalan yang luasannya mendominasi didesa dikurangi atau dirubah sebagian lahannya menjadi area vegetasi baik berupa hutan atau kebun yang selanjutnya dilakukan penghijauan atau reboisasi untuk menjadi area resapan (Qrv). lahan permukiman yang mejadi area limpasan dibangun 
sumur resapan di setiap rumah atau bangunan beratap sebagai kontruksi resapan (Qsr), lahan sawah pertanian yang juga mendominasi lahan didesa dibangun sumur injeksi di setiap sebagai kontruksi resapan (Qsi). Kombinasi model resapan tersebut untuk mereduksi debit limpasan air hujan atau debit puncak banjir (Qth) agar berada dibawah kapasitas sungai (Qks) jika dirumuskan model reduksi desa spons menjadi sebagai berikut:

1. Qth - Qms $<$ Qks

2. $\mathrm{Qms}=\mathrm{Qrv}+\mathrm{Qsr}+\mathrm{Qsi}$

3. Qth $-($ Qrv + Qsr + Qsi $)<$ Qks

Dengan sistem reduksi model desa spons (Qms) dapat dibuktikan bahwa setiap desa dalam kawasan DAS memilki kemampuan dalam meresapkan (mereduksi) limpasan air hujan, sehingga setiap desa berfungsi sebagai Unit resapan. Model ini dapat mengatasi banjir dengan mereduksi banjir sampai $73.14 \%$ untuk debit rancangan $\mathrm{Q}_{25}$ th, dan dapat mereduksi banjir hingga $78.14 \%$, Untuk debit banjir $\mathrm{Q}_{50 \text { th }}$ sebagaimana gambar 7 grafik hidrograp berikut ini yang menunjukkan penurunan puncak banjir untuk $\mathrm{Q}_{50 \text { th }}$ semula $569.2 \mathrm{~m}^{3} / \mathrm{dtk}$ menjadi $124.4 \mathrm{~m}^{3} / \mathrm{dtk}$ dibawah Debit kapasitas sungai $\mathrm{Q}_{\mathrm{ks}}=136.5 \mathrm{~m}^{3} / \mathrm{dtk}$ atau $\mathrm{Q}_{50 \mathrm{th}}-\mathrm{Q}_{\mathrm{ms} 5}<\mathrm{Q}_{\mathrm{ks}}$

HIDROGRAP PENURUNAN DEBIT PUNCAK (Q50th) BANJIR SETELAH DIREDUKSI MODEL SPONS (Qms5)

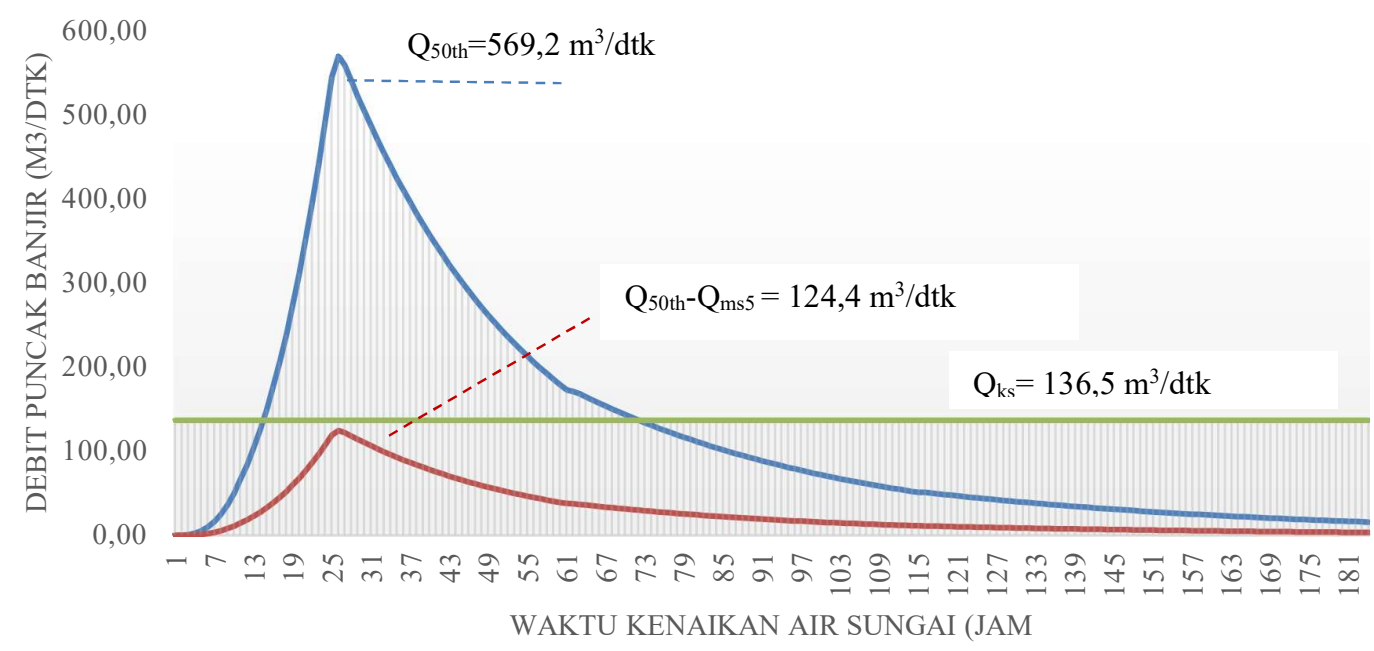

Q50th Q Q50th-Qms5 Qks

Gambar 7. Hidograf penurunan debit puncak (Q50th) setelah direduksi model desa spons.

Dari Gambar 7 diatas dapat diperhatikan bahwa semula debit puncak banjir $\mathrm{Q}_{50 \text { th }}=569.2$ $\mathrm{m}^{3} / \mathrm{dtk}$ dapat direduksi sampai $78.14 \%$ hingga menjadi $124.4 \mathrm{~m}^{3} / \mathrm{dtk}<\mathrm{Qks}=136.5 \mathrm{~m}^{3} / \mathrm{dtk}$ dibawah kapasitas sungai. Dengan kata lain kota Sampang dapat terbebas dari banjir apabila dibuat konsep model desa spons berbasis ecodrains, model ini dibentuk dengan membuat semua desa di area kawasan DAS yang semula menjadi desa penyebab banjir atau desa limpasan air hujan dirubah menjadi desa yang dapat menyerap air hujan seperti halnya spons sehingga ketika terjadi hujan yang lebat dan merata semua desa yang ada dikawasan DAS mereduksi limpasan air hujan yang terjadi sehingga aliran yang masuk ke anak sungai dan sungai utama tidak melampaui batas kapasitas sungai, jika aliran air yang mengalir di sungai tidak melebihi batas kapasitas sungai maka tidak akan terjadi luapan yang berakibat banjir.

Model desa spons adalah model desa resapan dikawasan DAS untuk mereduksi limpasan hujan dan mencegah banjir agar debit limpasan yang mengalir terkendali berada dibawah kapasitas sungai, dengan pengaturan pola ruang desa sebagai berikut $40 \%$ lahan didesa nya untuk vegetasi baik dengan penghijauan atau reboisasi hutan, $15-25 \%$ untuk lahan Permukiman dengan dibangun sumur resapan pada setiap rumah/ bangunan beratap, $15-30 \%$ dari luas desa untuk sawah pertanian dan dibangun sumur injeksi disetiap 0.16 ha, lahan tegalan atau lahan kosong dibatasi maksimal $25 \%$ 
dari luas desa dengan ditanamani rumput atau tanaman penutup. Berikut model pola ruang desa spons dengan sistem resapannya dalam mengatasi banjir sekaligus menjadi model keterbaharuan dalam menyelesaikan banjir untuk diterapkan disemua desa kawasan DAS yang bermasalah dengan banjir dan kekeringan. Model Tata ruang desa untuk pengendalian banjir yang sangat baik dalam mereduksi banjir ditunjukkan sebagaimana pada gambar 8 berikut ini

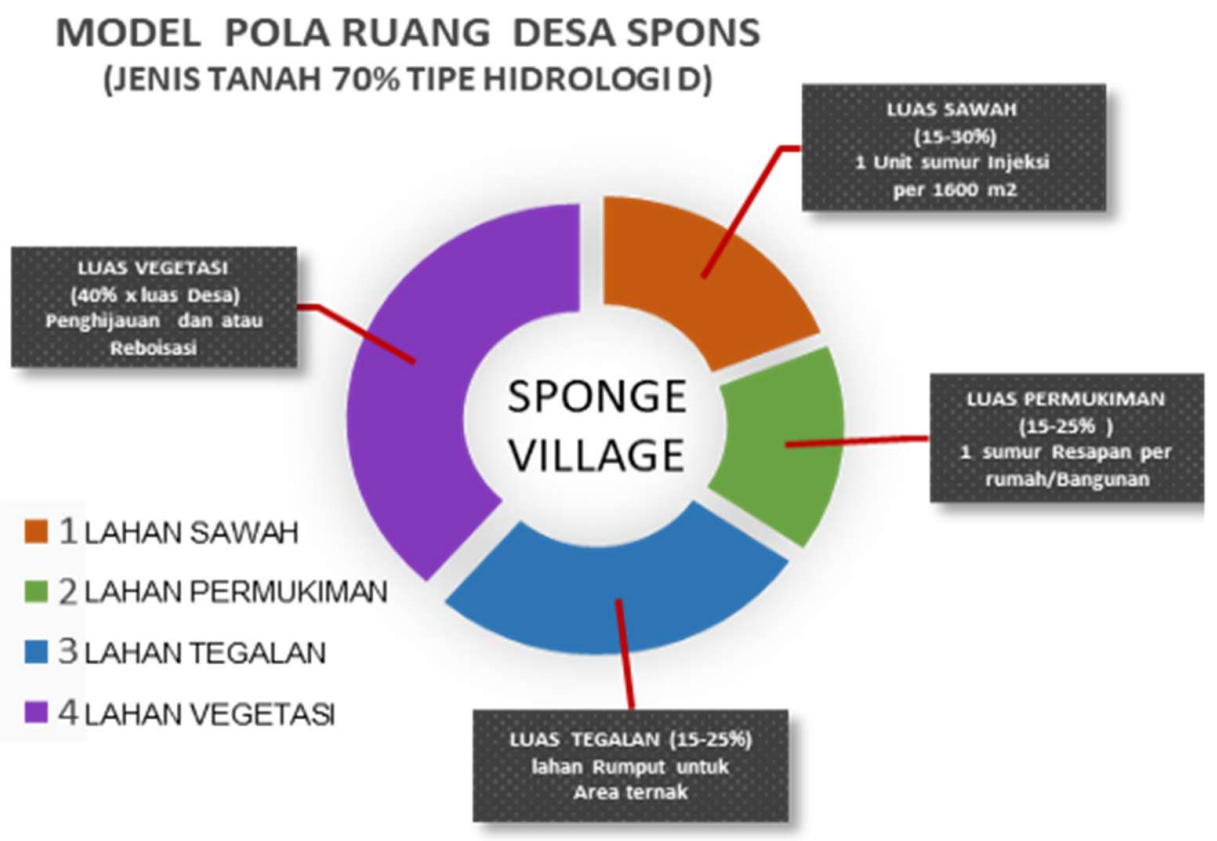

Gambar 8. Model Pola Ruang desa spons dalam mengatasi banjir

Dari Gambar 8 diatas dapat diperhatikan bahwa komposisi lahan didesa akan ramah lingkungan atau aman dari limpasan hujan berlebih serta aman dari kekeringan apabila diberlakukan penerapan model pola ruang desa sebagaimana gambar diatas yang dikhususkan untuk area desa di kawasan DAS dalam upaya pencegahan banjir dan penerapan 5 pilar pengelolaan SDA dan pengelolaan DAS guna mengurangi kerusakan lingkungan dengan penerapan pola ruang desa sebagaimana Gambar 8 diatas tidak hanya menjadi desa pencegah banjir maka juga menjadi desa yang dapat mengatasi masalah kekeringan yang menjadi masalah perubahan iklim saat ini..

Penerapan model desa spons ini akan menciptakan iklim baru yang lebih kondusif terhadap lingkungan di DAS yang dimulai di dari Desa. Lebih implementatif dengan pengaturan tata ruang didesa yang banyak belum tersentuh oleh pemerintahan desa, kecamatan dan kabupaten. Sebagaimana disampaikan oleh Faisal Riza, (2016) dalam karya ilmiahnya tentang Tinjauan Hukum tentang urgensi pengaturan tata ruang desa yang mengatakan bahwa" Pengaturan tata ruang desa pada dasarnya hingga saat ini belum ada pengaturan khusus. Pengaturan tata ruang saat ini menjadi sesuatu yang penting dan urgensi. karena 3 alasan yakni untuk pembuatan RPJMDes guna melindungi ekosistem dan sumberdaya desa, ketiadaan tata ruang desa menimbulkan konflik antar desa dan kerusakan lingkungan seperti penebangan pohon, galian golongan $\mathrm{C}$ yg liar di area perbukitan/pegunungan maupun sungai atau kali. Rencana tata ruang yang ada selalu membagi desa dan perkotaan, sementara desa tidak tersentuh unit teritorialnya dan sedikit yang menyadari bahwa awal mula limpasan air hujan berasal dari desa dihulu DAS, dan kota yang ada dihilir DAS selalu menerima dampaknya ketika terjadi banjir.

\section{Kesimpulan}

Dari hasil analisa perhitungan diatas diketahui bahwa dengan memperbanyak luasan vegetasi yang dilakukan disetiap desa dalam kawasan di DAS lebih mudah dalam implementasi penanaman 
tanamannya (penghijauan/reobisasi) dan didapat kondisi optimum luas vegetasi terbaik yakni seluas $40 \%$ dari luas desa atau seluas $40 \%$ dari luas DAS kondisi pola ruang tersebut sudah dapat mengatasi banjir debit $\mathrm{Q}_{2 \text { th }}$ walau jenis tanah $72 \%$ tergolong hidrologi $\mathrm{D}$. Untuk dapat mengatasi jenis banjir yang beintensitas lebat (debit $\mathrm{Q}_{5 \text { th }}$ keatas) dengan kondisi tanah $72 \%$ tergolong kelompok laju infiltrasi sangat lambat. Dilakukan dengan penambahan sistem kombinasi resapan yang berbasis ecodrainase yakni penambahan sumur resapan dipermukiman dan sumur injeksi di area sawah pertanian, dengan pengaturan tata ruang desa secara proporsional. Sebagiamana rencana pola ruang desa spons. Apabila mengikuti pola ruang model desa spons maka banjir hingga $\mathrm{Q}_{50 \text { th }}$ dapat diatasi dengan baik. Kelebihan Pengendalian banjir model desa spons ini adalah selain berkonsep ramah lingkungan dan tidak perlu pembebasan tanah proses implementasi dilapangannya akan lebih mudah dibandingkan dengan pengelolaan DAS secara konvensional yang mana pelaksana atau pengelola dilapangannya selalu mengalami kesulitan karena luas DAS yang terlalu besar, sementara untuk model desa spons dapat menganggap semua wilayah desa menjadi unit wilayah DAS. Dengan adanya Perangkat Desa dan Aparat Desa yang sudah ada dan lebih mudah dalam mengoptimalkan pola pemberdayaan masyarakat Desa.

\section{Daftar Pustaka}

Anis, Bariroh, Mizun,, suharjono, Ussy Andawayanty 2017, Kolam Tampungan sebagai Pengendali banjir di Kecamatan Sampang, Jurnal Teknik Pengairan vol 8 no.1 (2017) Universitas Brawijya malang, malang.

Asdak, chay 2002, Hidrologi dan Pengelolaan Daerah aliran Sungai, gajah mada University Press, Yogyakarta.

Agustini,Liana \& Nadjajdi, 2016, Pengelolaan Tâta Guna lahan sebagai Penanganan banjir di DAS Kamoning Sampang, Tesis, Magister Institut teknologi Sepuiuh Nopember, Surabaya.

Bhakti, P.P, 2008. Konsep pemanfaatan ruang untuk pengendalian banjir di Sub Sistem Pematusan Gunung Sari-Balong sari Surabaya Tesis, magister : Institute Teknologi Sepuluh Nopember, Surabaya

Bisri,Mohammad, 2009, Pengelolaan Daerah Aliran Sungai, Malang, PenerbitCV.Ansori, Malang.

Harisuseno,D, Bisri M et.al, 2014. Analisa Spasial Limpasan Permukaan Menggunakan Model Hidrologi diwilayah Perkotaan, Journal of Envirommental Engineering and sustainable Teknology (Jeeest) vol.1 no.1 (2014)

Sosrodarsono, S dan Kensaku Takeda,2003 Hidrologi untuk pengairan, Jakarta, penerbit PT.Pradiya Paramita,

Sugandi, Dede, 2007, Model Penanggulangan banjir, Universitas Gajah mada, Yogyakarta.

Riza, Faisal, 2017 , "Tinjauan Hukum tentang Urgensi Pengaturan Tata Ruang desa”,Jurnal mahasiswa S2 Hukum UNTAN "Jurnal Nestor Magister Hukum, Vol 2, no,2 (2017)

Tritwidiyanto, Afrizal, 2013, "Pemitaan Resiko bencana Banjir akibat luapan Sungai Kemoning Kabupaten Sampang", Skripsi Sarjana, Universitas Diponegoro, Semarang.

Undang-Undang Republik Indonesia No. 6 Tahun 2014 Tentang Desa.

Undang-Undang Republik Indonesia no. 7 tahun 2004 tentang Sumber Daya Air. 